\title{
Bulk Preparation of Radiation Crosslinking Poly (Urethane-Imide)
}

\author{
Chengfei Zhou
}

Additional information is available at the end of the chapter

http://dx.doi.org/10.5772/48282

\section{Introduction}

Ionizing radiation can be used for understanding mechanism of polymerization reaction as well as for initiation of the polymerization process. Some of the advantages of the radiation initiated polymerization over conventional methods are: (i) absence of foreign matter, like initiator, catalyst, etc., (ii) polymerization at low temperature or in solid state, (iii) rate of the initiation step can easily by controlled by varying dose rate and (iv) the initiating radicals can be produced uniformly by $\gamma$-irradiation. The gamma ray induced radiation polymerization, broadly speaking, in addition to the narrow sense "radiation polymerization (also known as radiation initiated polymerization. That is, using high energy ionizing ray to irradiate monomers, and generates ions or radicals, so that form the active center and the polymerization reaction.), also includes the radiation graft polymerization and radiation crosslinking polymerization, etc. [1-18].

Indeed, radiation crosslinking polymerization is one of the important research fields of radiation polymerization. Remarkably, the radiation crosslinking polymerization has been great development since Charles found polyethylene radiation effect and predict these radiation effects may lead to industrial applications. Radiation crosslinking polymerization can be carried out in solution, can also be carried out by bulk polymerization. Radiation crosslinking via bulk polymerization is relatively simple and has the advantages of high product purity. Therefore, as a powerful means for modification of polymerric materials to be widely applied in many fields, and, radiation crosslinking modification of polyurethanes is one of most important aspects [19-34].

In the study of the radiation crosslinking polyurethane, a lot of work was done in polyurethane synthesis, in its molecular backbone to import some unsaturated bond, application of $\gamma$-irradiation to realize the radiation crosslinking in order to obtain a better crosslinking effects, improved thermal stability and other properties of polyurethane. There 
are reports, in polyurethane molecular backbone structure into the diacetylene moieties, by ray irradiation, the diacetylene moieties can produce crosslinking polymerization (often called "cross polymerization") and the formation of covalently crosslinked conjugated polydiacetylene network [35-47]. And studies show that, if the polyurethane main chain structure is only hard segment containing unsaturated bond, then after irradiation, often produce crosslinking reaction only in hard segment microdomains, and the glass transition temperature ( $\mathrm{Tg}$ ) of the soft segment can remain unchanged. In addition, in recent years, the study of the radiation crosslinking polyurethane is also extended to the field of poly(urethane-imide)(PUI)[48].

\section{Preparation foundation of radiation crosslinking poly(urethane - imide)}

Poly (urethane -imide) is a new polymeric material, it has the excellent properties of both polyurethane and polyimide, such as good mechanical properties, thermal stability, high mechanical strength, electrical insulating properties, chemical resistance, hydrolysis resistance, radiation resistance, abrasion resistance and biological compatibility, etc. Poly (urethane-imide) is a block copolymer comprised of flexible chain segment and rigid chain segments. However, in the block structure of poly(urethane-imide), the rigid chain segment is polyimide [49-67]. Moreover, the bulk preparation of radiation crosslinking poly(urethane-imide) is also based on the bulk preparation of polyurethane. Therefore, here to discuss the bulk preparation of radiation crosslinking polyurethane before other description.

Radiation crosslinking polymerization of polyurethane is often to achieve via unsaturated bonds of molecular backbone structure, in addition, also to carry out by the introduction of unsaturated terminal using end capping methods, and, also to enhanced radiation crosslinking polymerization by adding crosslinking agent in the system. In our study, mainly through the preparation of double terminated polyurethane to realize its radiation crosslinking polymerization[68], specific method as shown in figure 1 . The specific method are: (i) using 2-hydrooxyethyl methylacrylate ( $\beta$-HEMA) as end capping agent, (ii) using bulk polymerization method to synthesize double terminated polyurethane prepolymer, (iii) adding crosslinking agent octavinyloctasilasesquioxane(OVS), (iv) by $\gamma$-irradiation, through free radicals react to form OVS-polyurethane crosslinked structure. The $\beta$-HEMA is a typical monomer, which are often used to radiation polymerization, here is to consider its hydroxyl groups can react with isocyanate groups, as end capping agent to use. Although the preparation of the OVS-polyurethane by radiation polymerization has been rarely reported, but there are many relevant reports $[69,70]$.

As an example, according to the above method, the radiation crosslinking polyurethane was prepared by using polycarbonate diol and liquefied 4, 4-diphenylmethane diisocyanate (Liquefied MDI). And, by $\gamma$-irradiation, radiation dose is $50 \mathrm{kGy}$, irradiation dose rate for $10 \mathrm{kGy} / \mathrm{h}$. And, the sample 1 is unirradiated polyurethane prepolymer, the sample 2 is the radiation crosslinking polyurethane elastomer (without OVS), the sample 3 and sample 4 
are the OVS-polyurethane radiation crosslinked samples (the adding quantity of OVS were $7 \%$ and $11 \%$, respectively). The structure and properties of obtained sample was investigated with Fourier transform infrared spectroscopy(FTIR), X-ray diffraction(XRD), dynamic thermomechanical analysis(DMA), and thermal gravimetric analysis(TGA).

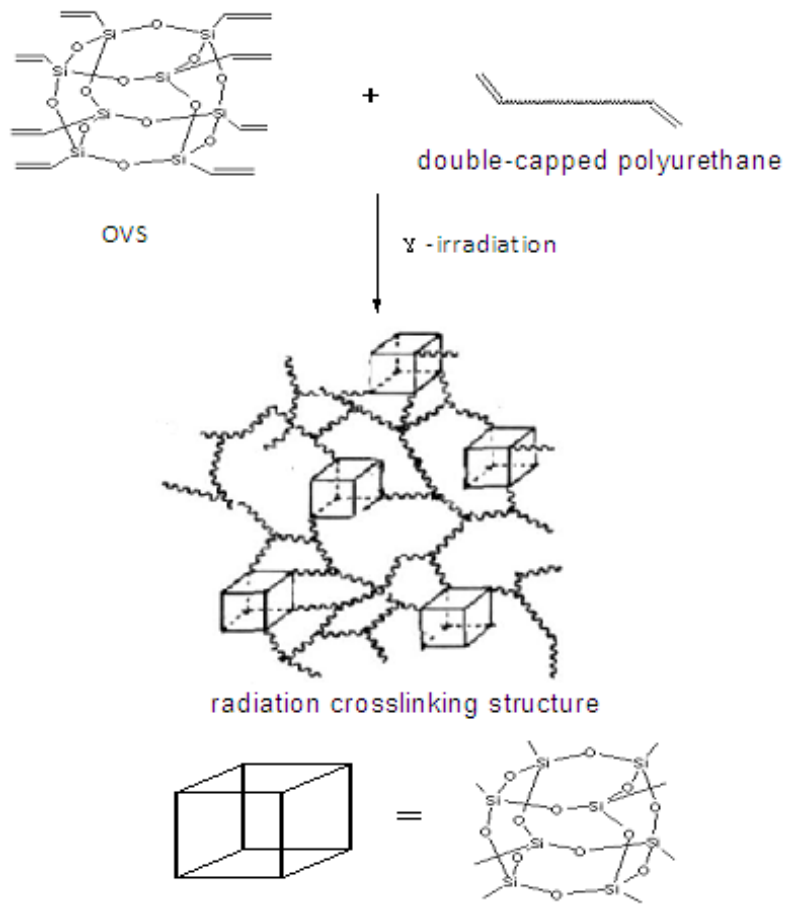

Figure 1. Schematic diagram of OVS-polyurethane radiation crosslinked system

Figure 2 is the FTIR spectra of the radiation crosslinking polyurethane. Unirradiated sample (sample 1), appears a weak absorption peak at $905 \mathrm{~cm}^{-1}$, which is the contribution of $\mathrm{C}=\mathrm{C}$ double bond, but in the irradiated samples (2, 3 and 4), the peak disappear, it is obvious that the formation of cross-linked structure is mainly due to the crosslinking reaction of the unsaturated double bonds. On the other hand, Figure 3 is the XRD spectra of the radiation crosslinking polyurethane. whether linear (unirradiated sample, sample 1) or radiation crosslinking (sample 2), only the one passivated diffraction peak, only the presence of local regular structure, and no obvious crystal phenomenon. However, the OVS-polyurethanes radiation crosslinking samples(3 and 4), appears sharp diffraction peaks in the diffraction angle of $7.9,8.8,10.9,11.7,18.4,19.9,21.9,24.3,25.5$, which belonged to the crystallization of OVS contained in OVS-polyurethane. In addition, Figure 4 is the TDA results of the radiation crosslinking polyurethane. Visible by the Figure 4, the thermal stability of radiation crosslinking polyurethane is greatly improved, the temperature of $5 \%$ weight loss for sample 2,3 and 4 are $269.6^{\circ} \mathrm{C}, 242.6^{\circ} \mathrm{C}$ and $239.0^{\circ} \mathrm{C}$, respectively, but the temperature of $5 \%$ weight loss of unirraded sample (sample 1 ) is only $133.3^{\circ} \mathrm{C}$. 


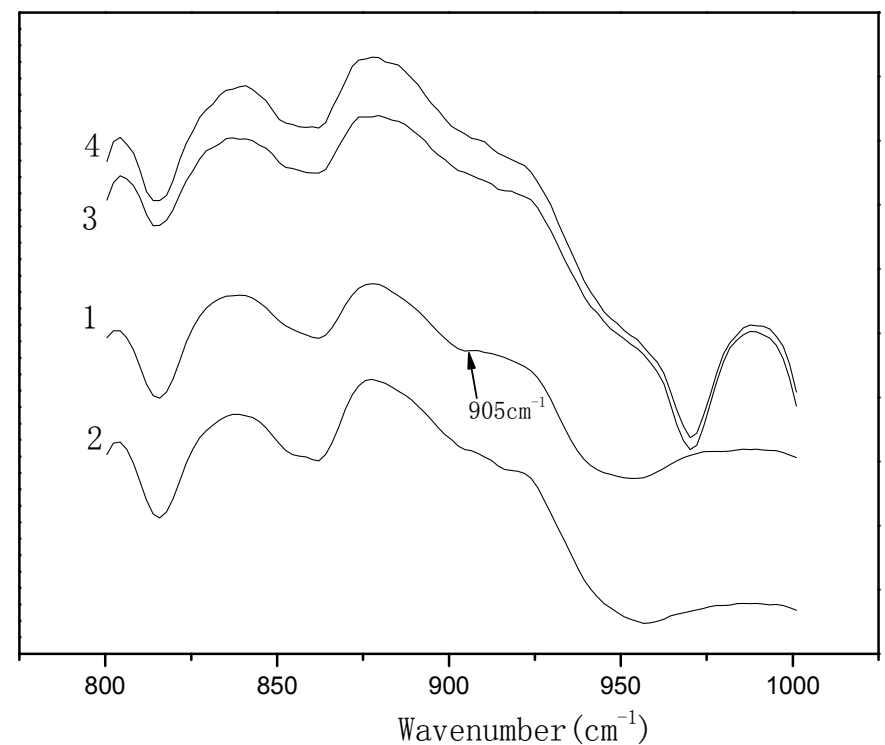

Figure 2. FTIR spectra of radiation crosslinking polyurethane

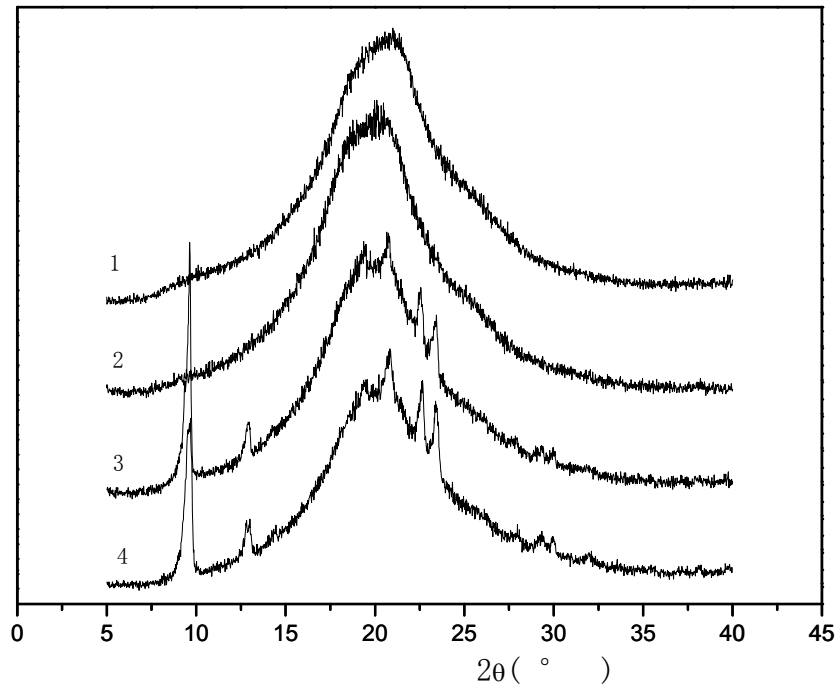

Figure 3. Figure $3 \mathrm{XRD}$ spectra of radiation crosslinking polyurethane 


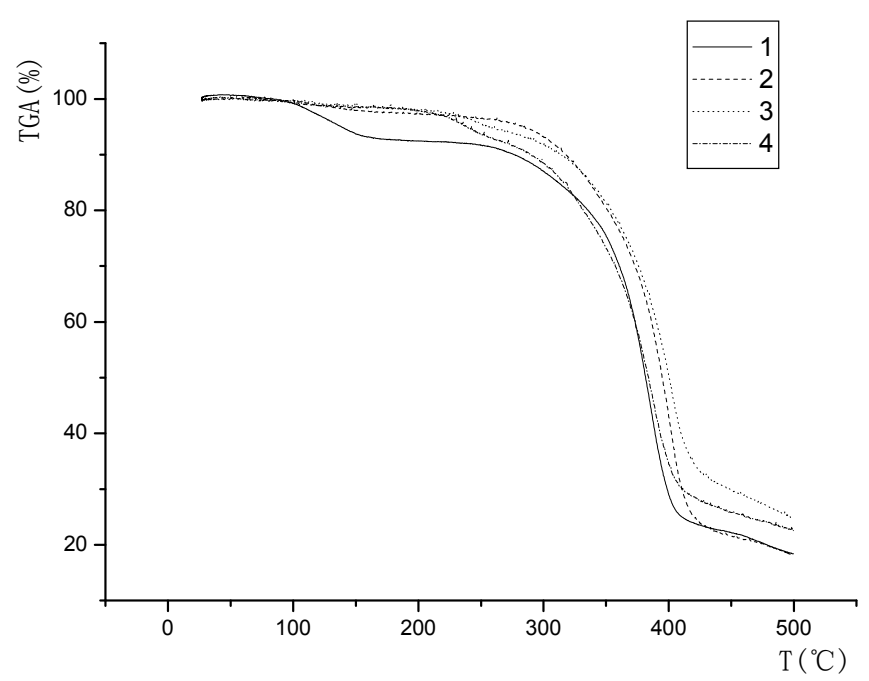

Figure 4. TGA curves of radiation crosslinking polyurethane

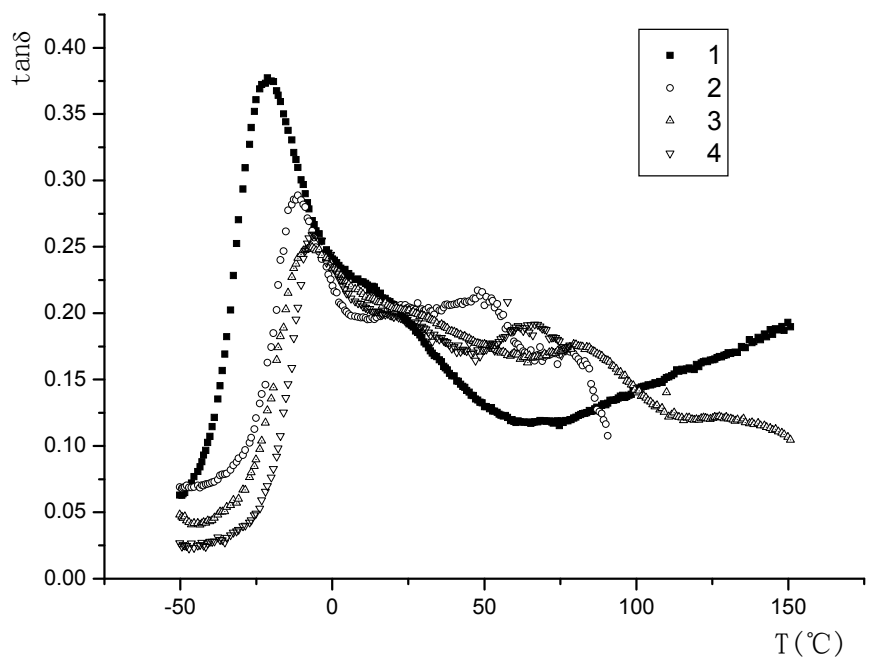

Figure 5. DMA charts of radiation crosslinking polyurethane

Figure 5 is DMA charts of radiation crosslinking polyurethane. The results show that, the tag $\delta$-T curves of the radiation crosslinking polyurethane are two tag $\delta$ peak. From the molecular structure of polyurethane, the flexible chain segment (often called soft segment) 
in macromolecules present random coil state, the soft segment and rigid chain segments (often called hard segment) of polyurethane are gathered in one block, forming the microphase separation structure. If the degree of phase separation is better, then the tag $\delta-T$ curve will appear the two tag $\delta$ peak, which belonged to soft segment and hard segment, respectively, but if between the two segment is compatibility, will become a tag $\delta$ peak. From that, the prepared radiation crosslinking polyurethane has a good degree of microphase separation. From Figure 5 it can be seen that, prior to irradiation (sample 1) ,only one tag $\delta$ peak from the soft segment, which is mainly the contribution of the long chain of polycarbonate diol. After irradiation (sample 2), because the $\beta$-HEMA polymerization and formation of polymeric chain segment, it appears a obvious tag $\delta$ peak due to poly(2-hydroxyethyl methacrylate) (PHEM) hard segment, and, the tag $\delta$ peak of soft segment shifts to higher temperature, which belonged to the confined effect of radiation crosslinking. After adding OVS, two tag $\delta$ peaks shift to more high temperature, and, the adding amount of OVS increased, this change more, This should be attributed to the contribution of OVS on radiation crosslinking polymerization.

\section{Radiation crosslinking of double bond teminated poly (urethane- imide)}

Already mentioned, the difference with polyurethane, the hard segment of poly (urethaneimide) is a polyimide. Then, during the preparation process of the radiation crosslinked poly (urethane-imide), to produce imide structure by the reaction of anhydride groups and isocyanate, thereby forming a polyimide hard segment, as shown in Figure 6. However, similar with polyurethane, if the molecular structure of poly(urethane-imide) does not contain unsaturated bond, it is difficult to achieve the ideal effect of radiation crosslinking polymerization. Therefore, the preparation of radiation crosslinking poly(urethane-imide), the same need to import some unsaturated group into its molecular backbone (soft segment or hard segment ) or its chain end, to enhance adiation crosslinking effect. In fact, so far, although preparation research of poly(urethane-imide) made a lot of progress[49-67], but report closely related with radiation polymerization also not too much.

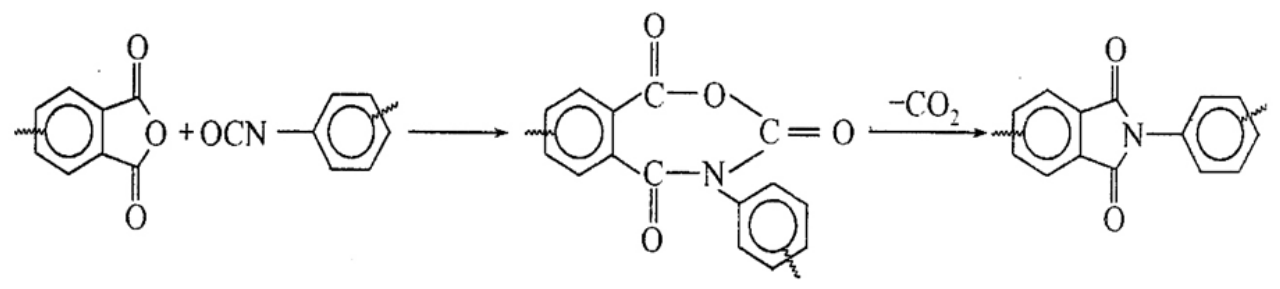

Figure 6. Schematic diagram of polyimide structure

Of course, we can prepare radiation crosslinking poly(urethane- imide) by using introduction of unsaturated bond into its molecular structure, especially hard segment structure, also through double end capping to prepare the radiation crosslinking 
poly(urethane-imide). This is because to analysis from the radiation crosslinking polymerization, the research ideas of radiation crosslinking poly(urethane-imide) should follow the basic preparation principle of polyurethane. However, in our study, mainly through the preparation of double bond terminated poly(urethane-imide) to realize radiation crosslinking polymerization, as shown in Figure 7 . The specific method are: (i) using $\beta$-HEMA as end capping agent, (ii)using bulk polymerization method to synthesize double terminated poly (urethane-imide), (iii) by $\gamma$-irradiation, to produce radiation crosslinking poly(urethane-imide).

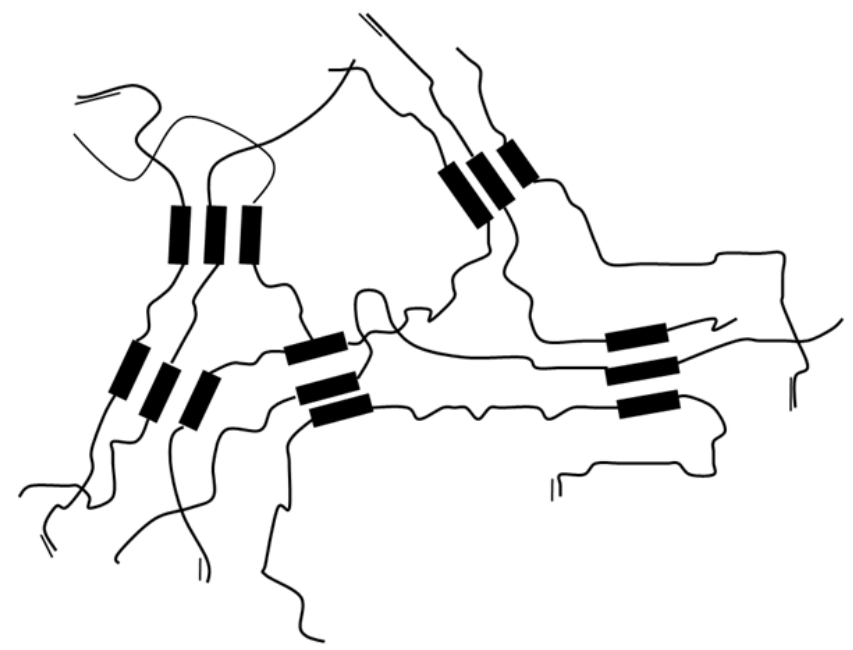

Figure 7. Schematic diagram of double capped poly(urethane-imide)

Here is to illustrate detailed preparation method via the specific discusstion. Radiation crosslinking poly(urethane-imide) was prepared using polycarbonate diol, pyromellitic dianhydride (PMDA) and hexamethylene diisocyanate (HDI). And, by using $\gamma$-irradiation, irradiation dose is $25 \mathrm{kGy}, 50 \mathrm{kGy}, 75 \mathrm{kGy}$ and $100 \mathrm{kGy}$, respectively, the irradiation dose rate for $10 \mathrm{kGy} / \mathrm{h}$. The structure and properties of obtained sample was investigated with FTIR, XRD, DMA, TGA and static thermodynamic analysis (TMA). Also, focus on the effect of radiation dose to the structure and properties of. radiation crosslinking poly(urethaneimide).

Figure 8 is the FTIR spectrum of the radiation crosslinking poly(urethane-imide), marked with the 0kGy for unirradiated poly(urethane-imide) sample. Figure 8 shows that, absorption peaks appeared at $1840 \mathrm{~cm}^{-1}$ and $1768 \mathrm{~cm}^{-1}, 1371 \mathrm{~cm}^{-1}, 1116 \mathrm{~cm}^{-1}, 730 \mathrm{~cm}^{-1}$, which may belong to the imine characteristic absorption of imine I, imine II, imine III and imine IV, respectively, the characteristic absorption peaks exist due to the poly(urethane-imide) sample does contain imide structure. In addition, the absorption peaks occurred at $3100 \mathrm{~cm}^{-1}$ and $1634 \mathrm{~cm}^{-1}$, the absorption peaks can be attributed to the characteristic absorption of the terminal unsaturated structure $(=\mathrm{C}-\mathrm{H}$ and $\mathrm{C}=\mathrm{C})$ in poly(urethane-imide) sample. In general, after irradiation, the most important reaction is radiation crosslinking and radiation 
degradation, and the unsaturated degree will also have some changes. From Figure 8 also shows, the absorption peaks of $=\mathrm{C}-\mathrm{H}\left(3100 \mathrm{~cm}^{-1}\right)$ and $\mathrm{C}=\mathrm{C}\left(1634 \mathrm{~cm}^{-1}\right)$, although declining with the increase of irradiation dose, but not too obvious.

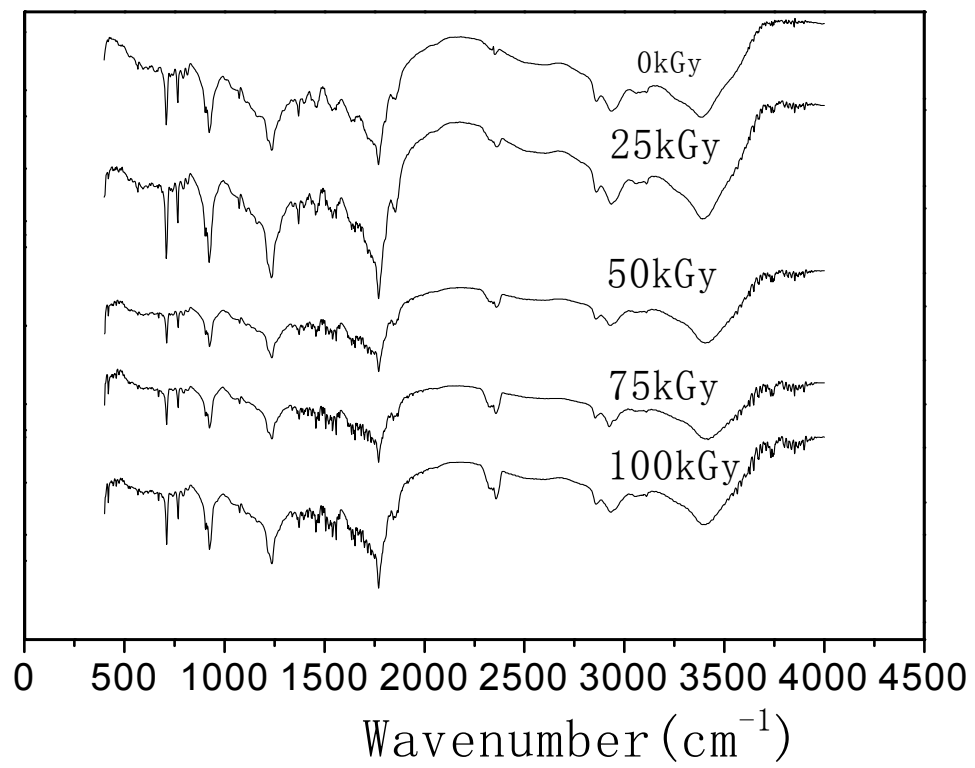

Figure 8. TIR spectra of poly(urethane-imide) with different irradiation dose

In addition, because of different kinds of isocyanate, long chain diols and anhydride, poly(urethane-imide) sometimes as amorphous but orderly structure, sometimes show some degree of crystallinity, this often is to analyze by using $X$ ray diffraction(XRD). As shown in Figure 9, the unirradiated poly(urethane-imide) sample(0kGy), appear sharp diffraction peaks at the diffraction angle of 14.3, 16.4, 20, 21.9, 27.5, 28.8 and 30, and, is dispersive diffraction peaks at the diffraction angle of 20, indicating that both local regular structure exist in the poly(urethane-imide) sample, but also has certain crystalline. However, the effect of $\gamma$-irradiation on the crystallinity of polymer, but more complex. In general, $\gamma$ irradiation led to crosslinking, will limit the crystal growth, so that the crystallinity decreased. In contrast, $\gamma$-irradiation induced degradation, the molecular weight is reduced, thus, molecular chain length is shorter, is conducive to the orientation and crystallization, thereby, in favor of crystallinity increased. Figure 9 shows, to irradiate by using irradiation dose of 25kGy, showed a strong sharp diffraction peaks at the diffraction angle of 20.3, but the intensity of this peak gradually reduced with the increase of radiation dose; and the intensity of the sharp diffraction peak at 21.9 is increased with the increase of irradiation dose; also to irradiate by irradiation dose of $100 \mathrm{kGy}$, this peak becomes very strong. In addition, when irradiation dose was 50kGy, a strong sharp diffraction peaks appeared at the diffraction angle of 18.3 , but other samples are not this peak, which may be to irradiate by 
irradiation dose of $50 \mathrm{kGy}$, is probably conducive to the formation of a specified level of crystalline structure.

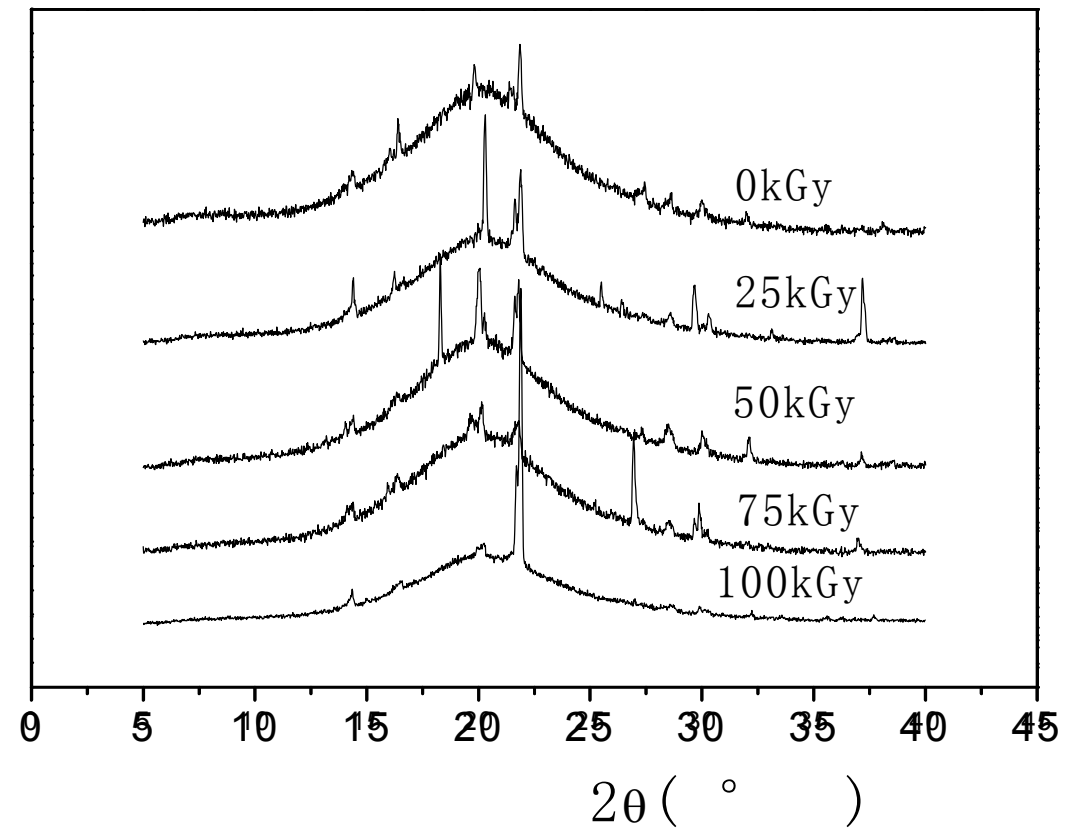

Figure 9. XRD spectra of poly(urethane-imide) with different irradiation dose

From the molecular structure of poly(urethane-imide), the carbamate bond, ether or ester bond all has the good flexibility, presents the random coil state, may be referred to as a flexible chain segment or soft segment; and imide chain segment is extended into a bar at ambient temperature, called the rigid chain segments or hard segment. And, the intermolecular cohesive energy and hydrogen bonding of the hard segment is enhanced by introduction of imide structure,. In this way, flexible chain segments and rigid chain segments are gathered in one block, forming the microphase separation structure. If the phase separation is better, then the two tag $\delta$ peak will appear in the DMA chart due to soft segment and hard segment, respectively, but if the phase separation of two segment is poor, will become a tag $\delta$ peak. As shown in Figure 10, a tag $\delta$ peak exist only in the tag $\delta$-T chart of unirradiated poly(urethane-imide) sample(0kGy), indicating certain compatibility between hard segment and soft segment. After irradiation, the tag $\delta$ peak was to shift to high temperature, and increased with the increase of irradiation dose, when the irradiation dose was $100 \mathrm{kGy}$, the tag $\delta$ peak shifts to approximately $150^{\circ} \mathrm{C}$; in addition, after irradiation, the peak value of tag $\delta$ decreased significantly, and the shape of tag $\delta$ peak is changed, when the irradiation dose was more than 50kGy, the tag $\delta$ peak appeared in the form of obvious shoulder peak. 


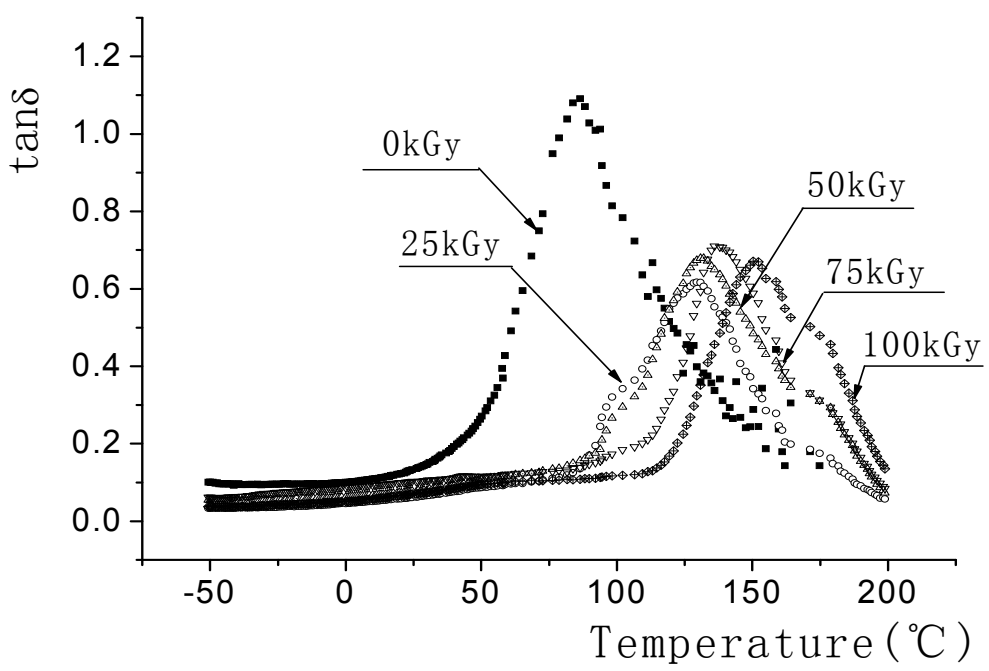

Figure 10. DMA charts of poly(urethane-imide) with different irradiation dose

\begin{tabular}{cccc}
\hline $\begin{array}{c}\text { Irradiation dose } \\
(\mathrm{kGy})\end{array}$ & $\begin{array}{r}\text { Temperature of } 5 \% \\
\text { weight loss }\left({ }^{\circ} \mathrm{C}\right)\end{array}$ & $\begin{array}{c}\text { Temperature of } 15 \% \\
\text { weight loss }\left({ }^{\circ} \mathrm{C}\right)\end{array}$ & $\begin{array}{c}\text { Temperature of } 50 \% \\
\text { weight loss }\left({ }^{\circ} \mathrm{C}\right)\end{array}$ \\
\hline 0 & 204.0 & 245.5 & 489.9 \\
25 & 210.2 & 283.8 & 494.3 \\
50 & 220.0 & 299.2 & 497.5 \\
75 & 220.3 & 306.8 & 496.4 \\
100 & 211.6 & 293.2 & 489.2 \\
\hline
\end{tabular}

Table 1. TGA results of poly(urethane-imide) with different irradiation dose

Also, from TGA test(table 1), to irradiate by using different radiation dose of 25kGy, 50kGy, $75 \mathrm{kGy}$, the thermal stability of radiation crosslinking poly(urethane-imide) is improved gradually, and, to achieve the best when the radiation dose was between 50kGy and 75kGy, this can be attributed to the degree of crosslinking increases with the increase of radiation dose. However, when irradiation dose was $100 \mathrm{kGy}$, the its thermal stability is worse than $75 \mathrm{kGy}$, may be the irradiation dose if too high, the degradation reaction will increase strongly, led to the degree of crosslinking drop. The TDA test ( Figure 11 ) also proved this point, that is to say, the radiation crosslinking poly(urethane-imide) obtained by the radiation dose of between $50 \mathrm{kGy}$ and $75 \mathrm{kGy}$, as has the best degree of cross-linking, thus has the best heat resistance. 


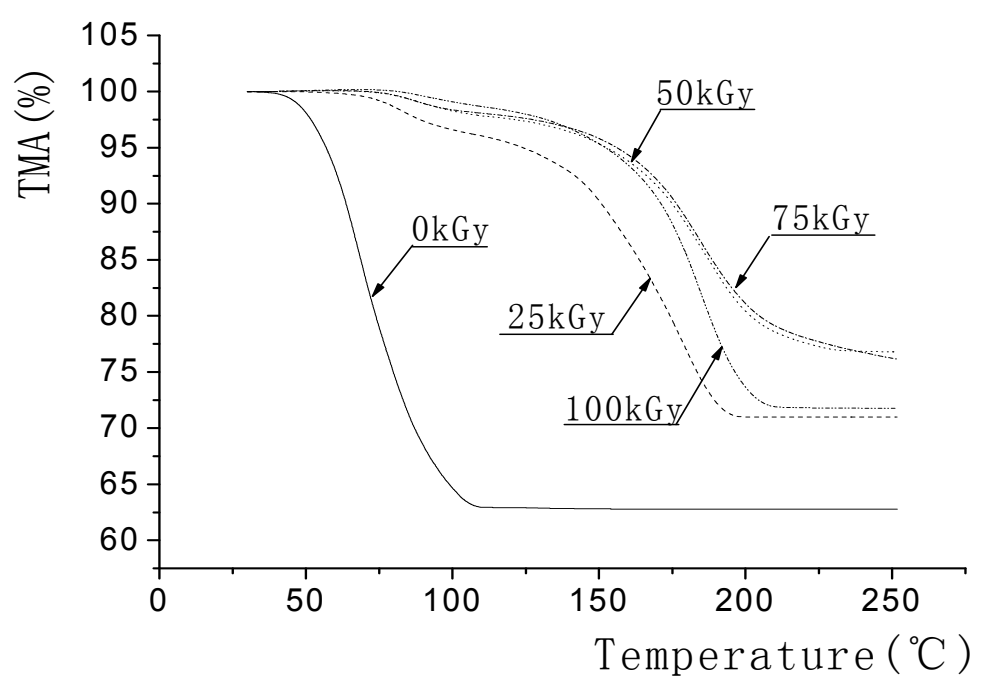

Figure 11. TMA charts of poly(urethane-imide) with different irradiation dose

\section{Radiation crosslinking OVS-poly (urethane-imide) foam}

In fact, radiation cross-linked poly (urethane imide) can be changed through the raw material and the conditions of the radiation crosslinking polymerization, to produce a variety of products with different properties. Can be prepared into high modulus specialty plastics, can also be prepared into high elastic rubber, but also can be made into films, fibers and foams, etc.. For the preparation of foam, can be made into rigid foam, can also be made into foamed elastomer. And, can also according to the specific requirement, made into a variety of foam products.

In the preparation of radiation crosslinked poly (urethane-imide) foams, can be achieved by the introduction of the unsaturated bond to the main chain molecular structure, can also be prepared via the double bond end capping. Moreover, can improve the effect of radiation crosslinking polymerization by adding a crosslinking agent. Also, the foaming problems of the poly(urethane-imide) foam can be solved using carbon dioxide gas (such as foaming agent $\mathrm{H}_{2} \mathrm{O}$ react with isocyanate to produce $\mathrm{CO}_{2}$, etc.). Here, only discuss the preparation of OVS-poly(urethane-imide) radiation crosslinking foam[71-73].

In the preparation of OVS-poly(urethane-imide) radiation crosslinking foam, specifically, was prepared using polyester polyol, polyphenyl polyisocyanate (PAPI), and 3,3',4,4'Benzophenonetetracarboxylic dianhydride(BTDA), and $\beta$-HEMA as end capping agent, adding crosslinking agent OVS. And, by using $\gamma$-irradiation, irradiation dose is $25 \mathrm{kGy}$, 50kGy, 75kGy and 100kGy, respectively, the irradiation dose rate for 10kGy / h. Also, focus 
on the effect of radiation dose to the structure and properties of. radiation crosslinking OVSpoly(urethane-imide) foam.

\begin{tabular}{ccccc}
\hline $\begin{array}{c}\text { Irradiation dose } \\
(\mathrm{kGy})\end{array}$ & $\begin{array}{c}\text { Temperature of } \\
5 \% \text { weight loss } \\
\left({ }^{\circ} \mathrm{C}\right)\end{array}$ & $\begin{array}{c}\text { Temperature of } \\
15 \% \text { weight loss } \\
\left({ }^{\circ} \mathrm{C}\right)\end{array}$ & $\begin{array}{c}\text { Temperature of } \\
50 \% \text { weight los } \\
\left({ }^{\circ} \mathrm{C}\right)\end{array}$ & $\begin{array}{c}\text { Temperature of } \\
80 \% \text { weight loss } \\
\left({ }^{\circ} \mathrm{C}\right)\end{array}$ \\
\hline 0 & 178.6 & 212.5 & 486.3 & 642.8 \\
25 & 186.2 & 222.3 & 515.1 & 640.8 \\
50 & 193.7 & 232.8 & 596.0 & 717.2 \\
75 & 189.1 & 220.6 & 508.6 & 644.6 \\
100 & 186.0 & 218.6 & 504.0 & 646.5 \\
\hline
\end{tabular}

Table 2. TGA results of radiation crosslinking poly(urethane-imide) foam

First, use TGA to explore the irradiation dose on the effect of the thermal stability of radiation crosslinking OVS-poly(urethane-imide) foam, in order to facilitate comparison, select four weight loss points of $5 \%, 15 \%, 50 \%$ and $80 \%$ to determine TGA temperature, the results are shown in table 2 . The results show that, when the weight loss was $5 \%, 15 \%, 50 \%$ and $80 \%$, respectively, the effect of irradiation dose all showed the same trend, namely, the corresponding TGA temperature increases with the increase of radiation dose, when the irradiation dose reaches $50 \mathrm{kGy}$, the TGA temperature reaches the maximum, then the TGA temperature drop with the increase of irradiation dose, and, the irradiation dose increased to higher, then more down low. Further analysis, the crosslinking structure between the vinyl group of OVS and terminal double bonds of poly(urethane-imide) will be formed by $\gamma$-irradiation, and the degree of crosslinking is closely related to radiation dose. If the irradiation dose is too small, the degree of crosslinking is insufficient, but if the irradiation dose is too large, the radiation degradation will increase, will cause the decrease of the degree of crosslinking, and this trend will increases with the increase of the irradiation dose.

Figure 11 is DMA charts of OVS- poly(urethane-imide) radiation crosslinking foam. First of all, from the relations of the irradiation dose and the elastic modulus ( $\left.E^{\prime}\right)$, the E' of the glassy state increased significantly with the increase of radiation dose, and when the irradiation dose was 50kGy, reached the maximum, and then, but decreased with the further increase of the irradiation dose, and, the irradiation dose increased, the E 'of the glass state is lower. This indicates that when the irradiation dose was 50kGy, the E' of the glassy stste was the highest. This can be attributed to the radiation dose of 50kGy can be the greatest degree of crosslinking, so that the foam has a high rigidity, also displays the maximum modulus. However, in the rubbery state, the effect of irradiation dose on the E' had no evident. Secondly, from the relations of the irradiation dose and the loss modulus ( E" ), the peak value of E" increases obviously with the increase of radiation dose, when irradiation dose was $75 \mathrm{kGy}$, reached the maximum, and then, the irradiation dose increased again, appeared in rapid decline. 

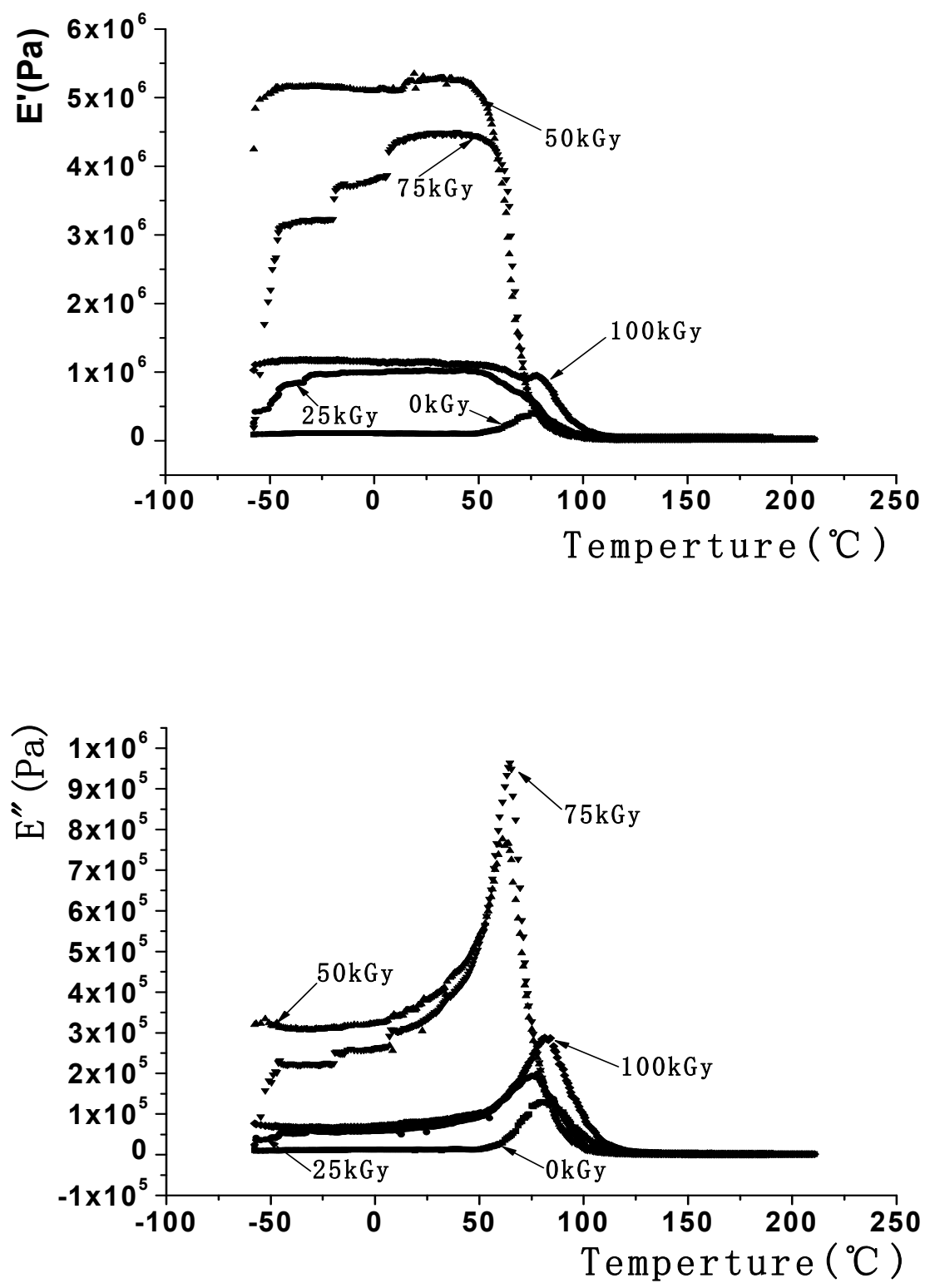

Figure 12. DMA charts of radiation crosslinking poly(urethane-imide) foam 


\section{Preparation of poly(urethane-imide) via other radiation polymerization}

In addition to the above method, Can also use other radiation polymerization method to prepare radiation crosslinking poly (urethane-imide). Such as the use of radiation crosslinking of organic polyols oligomer to obtain. Among them, Can be the first to use $\gamma-$ irradiation to produce radiation crosslinked organic polyol, as shown in Figure 13, then the radiation crosslinking poly (urethane-imide) prepared by radiation crosslinked organic polyol. Of course, this method, the application of the organic polyols oligomer containing unsaturated bonds would be more effective.

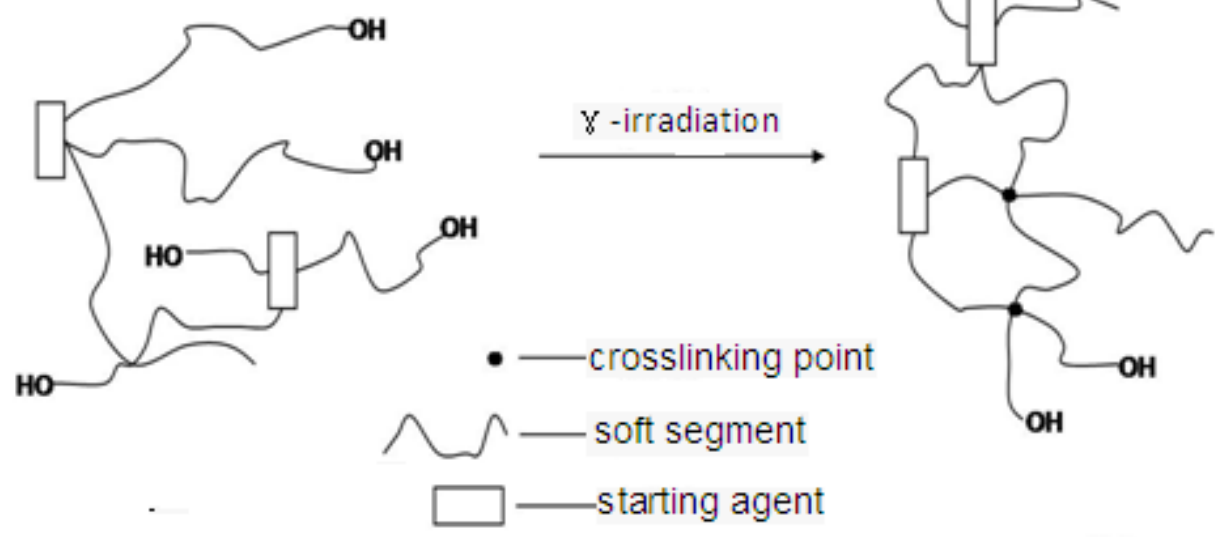

Figure 13. Schematic diagram of radiation crosslinking organic polyol

\begin{tabular}{cccccccc}
\hline \multirow{2}{*}{ Sample } & \multicolumn{7}{c}{ Viscosity $\left(\mathrm{mPa} \mathrm{s}, 25^{\circ} \mathrm{C}\right)$} \\
\cline { 2 - 7 } & $0 \mathrm{kGy}$ & $25 \mathrm{kGy}$ & $50 \mathrm{kGy}$ & $75 \mathrm{kGy}$ & $100 \mathrm{kGy}$ & $125 \mathrm{kGy}$ & $150 \mathrm{kGy}$ \\
\hline Polyether polyol & 724 & 886 & 960 & 1210 & 1250 & 973 & 959 \\
Rosin ester polyol & 10170 & 10510 & 10640 & 12420 & 12540 & 12060 & 10890 \\
\hline
\end{tabular}

Table 3. Effect of irradiation dose on viscosity of organic polyol

In which, we choose the rosin ester polyol (molecular backbone containing heterocyclic structure ) and a polyether polyol, to execute radiation crosslinking modification by using $\gamma$ irradiation, irradiation dose is $25 \mathrm{kGy}, 50 \mathrm{kGy}, 75 \mathrm{kGy}, 100 \mathrm{kGy}, 125 \mathrm{kGy}$ and $150 \mathrm{kGy}$, respectively, irradiation dose rate for $10 \mathrm{kGy} / \mathrm{h}$. And through the viscosity measurement to inspect the viscosity changes of organic polyols after irradiation, which explore the irradiation effect, experimental results as shown in Table 3. The results show that, polyether polyol and rosin ester polyol are all the same, that is, the viscosity increase with the increase 
of irradiation dose, and when the radiation dose was $100 \mathrm{kGy}$, reached the maximum, but then the viscosity will gradually decline with the increase of irradiation dose. The increase of viscosity can be considered to be caused by radiation crosslinking, so that to achieve the best crosslinking effect when the radiation dose was $100 \mathrm{kGy}$. In addition, the poly (urethane-imide) foams also has prepared using the obtained radiation crosslinking polyols(radiation dose for 100kGy), and, the properties of the obtained foams are shown in table 4.

\begin{tabular}{ccccc}
\hline Sample & $\begin{array}{c}\text { Density } \\
\left(\mathrm{g} / \mathrm{cm}^{3}\right)\end{array}$ & $\begin{array}{c}\text { Open cell content } \\
(\%)\end{array}$ & $\begin{array}{c}\text { Oxygen index } \\
(\%)\end{array}$ & $\begin{array}{c}\text { Temperature of 5\% weight } \\
\text { loss }\left({ }^{\circ} \mathrm{C}\right)\end{array}$ \\
\hline $\begin{array}{c}\text { polyether polyol } \\
\text { rosin ester } \\
\text { polyol }\end{array}$ & 0.030 & 91.9 & 34 & 184.4 \\
\hline
\end{tabular}

Table 4. Properties of radiation crosslinking poly (urethane-imide) foam

On the other hand, there is also an important method, which can be generally processed by $\gamma$-irradiation used for preparation of polymer polyols(POP) [74,75], and then to prepare poly (urethane-imide) by the POP. The $\gamma$-irradiation preparation of polymer polyol not only includes the radiation grafting and other radiation polymerization, moreover, these radiation reactions are carried out in special dispersion medium (organic polyol), which having a specific significance in radiation polymerization. Therefore, it is very necessary to elaborate.

Polymer polyol can be prepared using in situ polymerization method, that is to say, the hydrogen atoms of methine in polyether backbone can be shifted by $\gamma$-irradiation, to generate macromolecular free radicals, and cause graft polymerization with vinyl monomers. However, for this method, because the chain transfer constant of methylene is very small, it is difficult to improve the solid content of polymer polyol. It is best method to import containing double polyether polyol, often referred to as" macromer technique" [76]. This method is firstly to prepare the macromonomer (polyether polyol containing double bonds), and add it in polyether polyols(often referred to as polyether matrix), and then, produce graft copolymerization with vinyl monomers (styrene(St) and acrylonitrile(AN)) by $\gamma$-irradiation. In this case, the preparation method of macromonomer has many, and, the preparation method as shown in Figure 14 is one of the most commonly used methods.
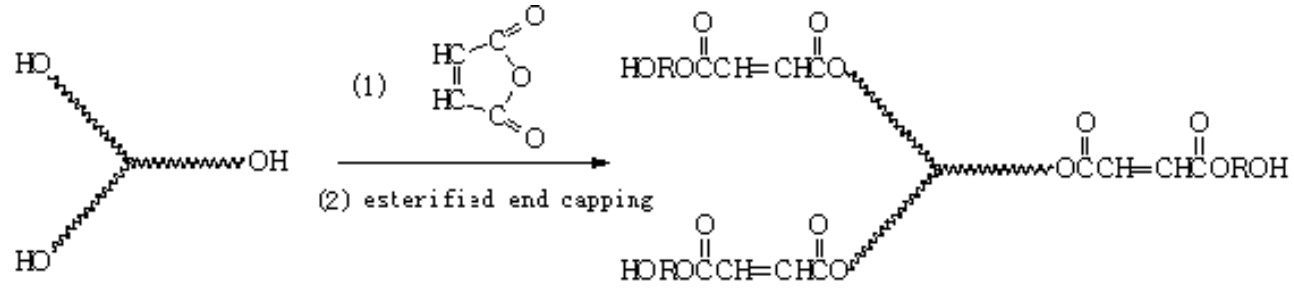

Figure 14. Schematic diagram of polyether macromonomer 
The radiation polymerization reactions in this method is given in figure 15 . In the obtained POP, the St-AN copolymer is present in the polyether matrix in the form of fine particles. The graft polyether due to radiation polymerization of macromonomer with St and AN, is to distribute on the surface of particle as steric stabilizer, as shown in Figure 16. As an example, first, to synthesize three kinds of macromonomer, Figure 17 is the FTIR spectrum of three kinds of macromonomer. And, styrene / acrylonitrile ratio is 55 / 45, the mixture of St/AN added based on the $55 \%$ of polyether matrix. And, by using $\gamma$-irradiation, irradiation dose is $5 \mathrm{kGy}$ and $25 \mathrm{kGy}$, respectively, the irradiation dose rate for $10 \mathrm{kGy} / \mathrm{h}$.
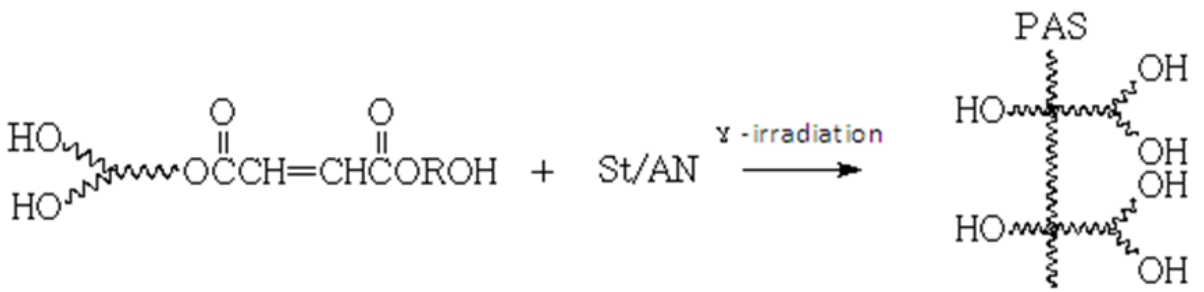

\section{Macromonomer}

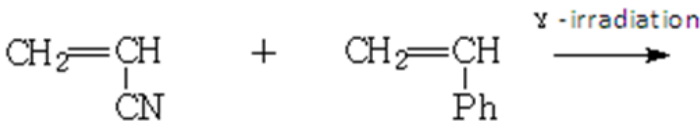

$(\mathrm{AN})$
Graft polyether<smiles>CCC(C#N)CC(C)c1ccccc1</smiles>

Figure 15. Schematic diagram of radiation polymerization reaction for preparing polymer polyol

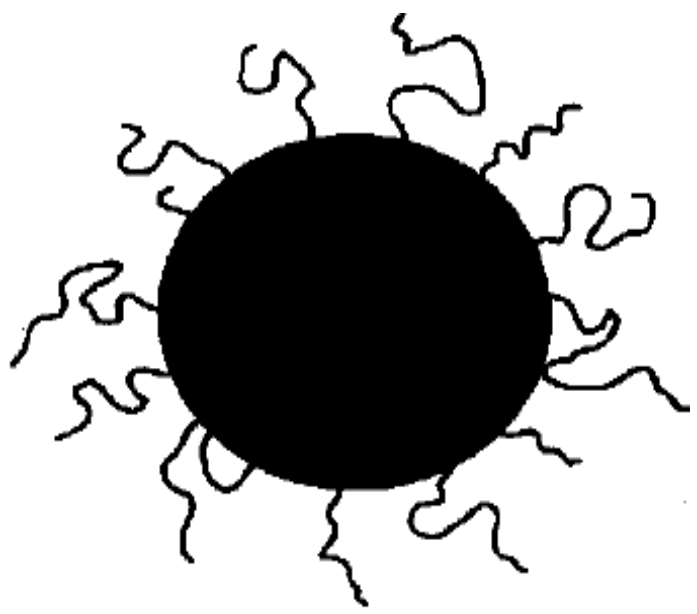

Figure 16. Schematic diagram of dispersion particle 


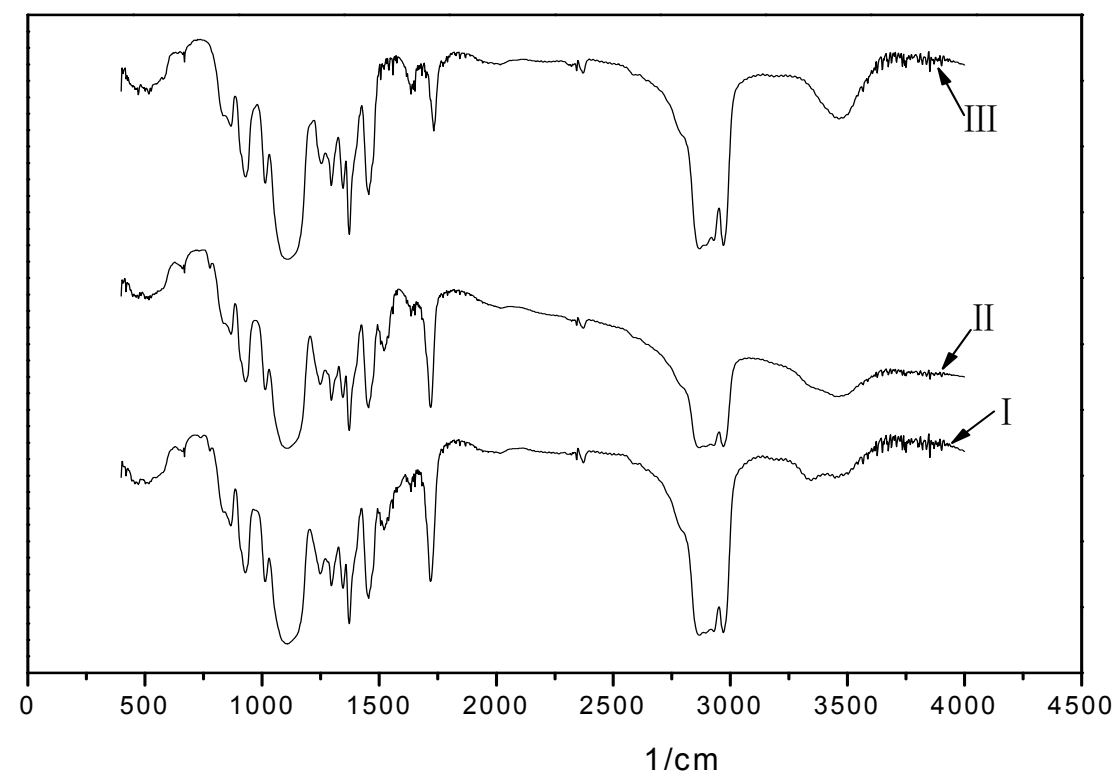

Figure 17. FTIR spectra of macromonomer

The dispersed phase particles of polymer polyols were isolated by high-speed centrifugation method, and, the morphological structure and properties of dispersed phase particles was investigated by Scanning electron microscope (SEM), XRD and DTA. Figure 18 is the SEM image for the dispersion particle, the results show that, the macromonomer and irradiation dose will influence the morphology of dispersed phase particles in polymer polyols. Among them, dispersion particle morphology has the more obvious difference for the polymer polyols using different macromonomer under the condition of $25 \mathrm{kGy}$. And, from the XRD measurement results (Figure 19), the irradiation dose also may affect the ordered structure of dispersed phase particles, This is because the shoulder peaks of the diffraction peaks appear more obvious in the low radiation dose (5kGy). In addition, from the DTA results as shown in Table 5, the radiation dose also have certain effect on the thermal stability of dispersed phase particles. The dispersion particles preparing at the higher radiation dose (25kGy) showed relatively better thermal stability.

Also, poly ( urethane-imide ) foams was prepared using the obtained polymer polyols, the some properties of the obtained foams are listed in table 6. The obtained poly ( urethaneimide ) foams has distinct characteristics, these particles can effectively play a reinforcing effect, especially it can remarkably improve the bearing capacity of foam. And, the its principle is also to follow a general theory of polymer composites. 


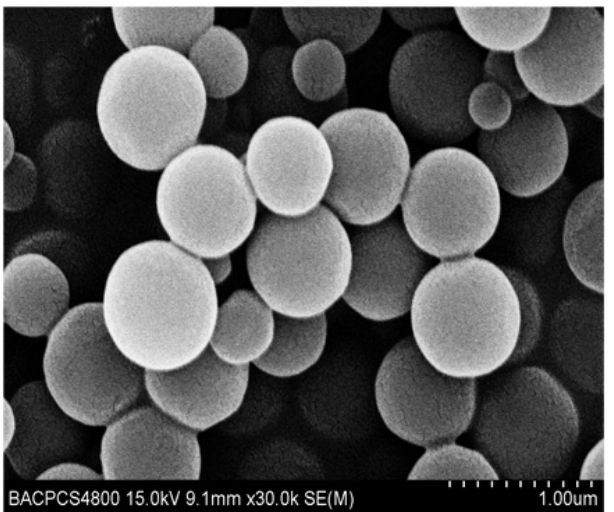

(I-1:Macromonomer I , Irradiation dose 5kGy)

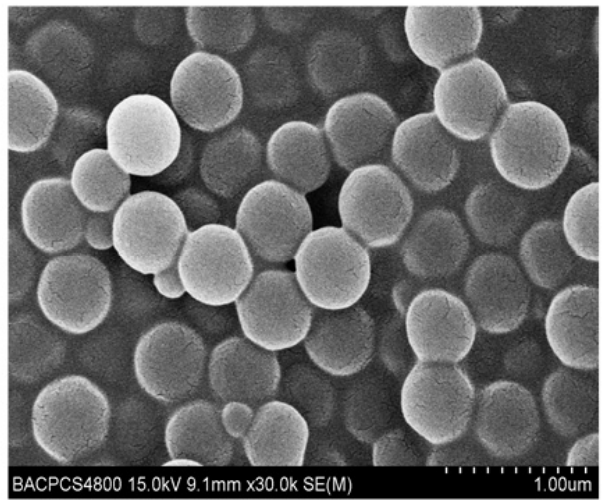

(II-1:Macromonomer II, Irradiation dose $5 \mathrm{kGy}$ )

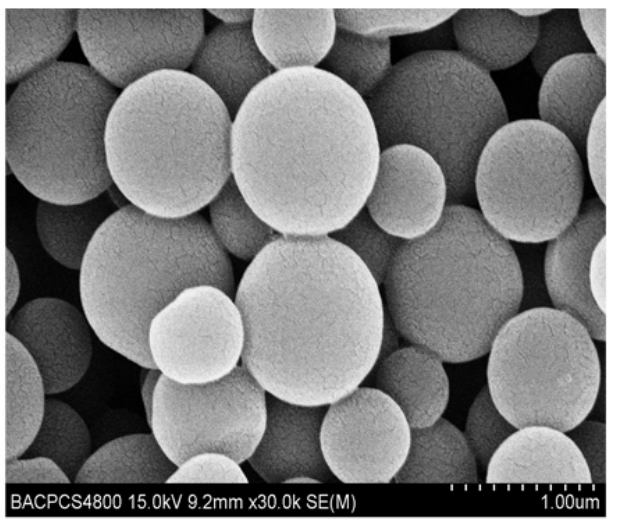

(III-1:Macromonomer III,Irradiation dose 5kGy) (III-2:MacromonomerIII,Irradiation dose 25kGy)

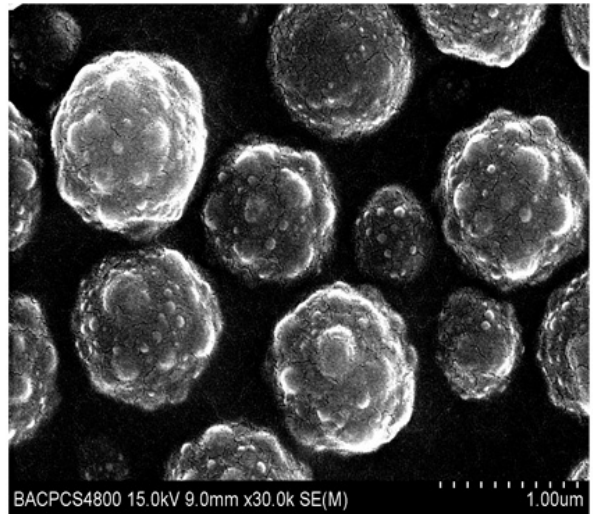

(I-2:Macromonomer I, Irradiation dose 25kGy)

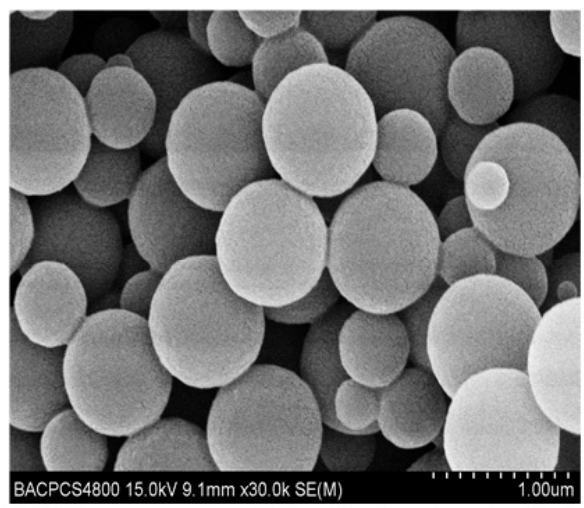

(II-2:Macromonomer II, Irradiation dose 25kGy)

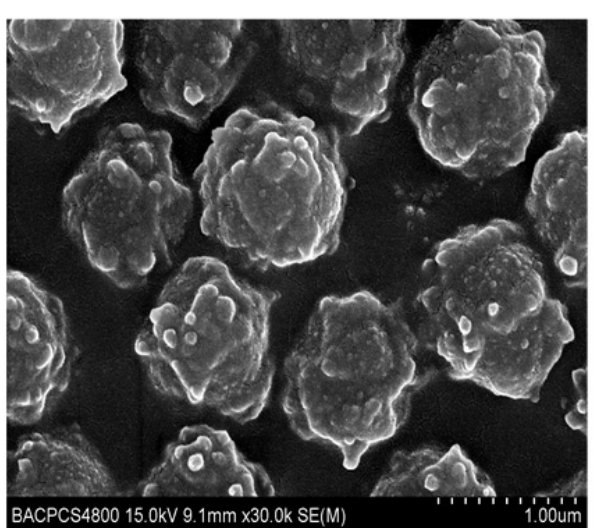

Figure 18. SEM image for dispersion particle 


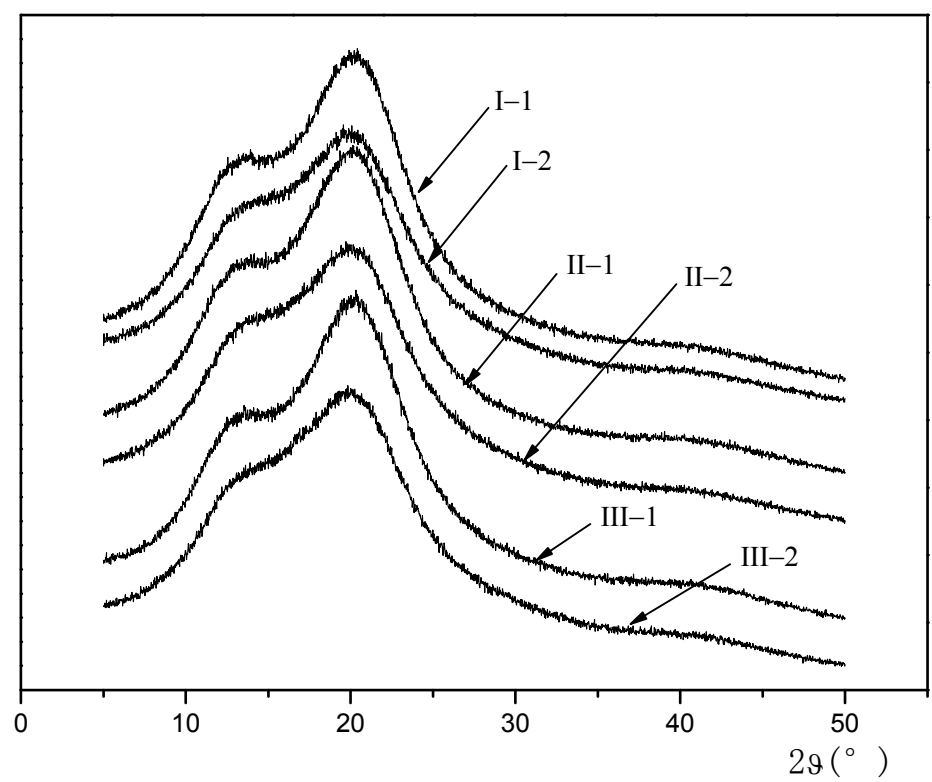

Figure 19. $\mathrm{XRD}$ spectra of dispersion particle

\begin{tabular}{ccccc}
\hline Sample & $\begin{array}{c}\text { Temperature of } \\
\text { 5\% weight loss } \\
\left({ }^{\circ} \mathrm{C}\right)\end{array}$ & $\begin{array}{c}\text { Temperature of } \\
\text { 15\% weight loss } \\
\left({ }^{\circ} \mathrm{C}\right)\end{array}$ & $\begin{array}{c}\text { Temperature of } \\
50 \% \text { weight loss } \\
\left({ }^{\circ} \mathrm{C}\right)\end{array}$ & $\begin{array}{c}\text { Temperature of } \\
80 \% \text { weight loss } \\
\left({ }^{\circ} \mathrm{C}\right)\end{array}$ \\
\hline I-1 & 370.7 & 398.2 & 426.0 & 441.4 \\
I-2 & 378.4 & 406.1 & 428.0 & 443.1 \\
II-1 & 323.0 & 368.1 & 410.8 & 429.9 \\
II-2 & 394.2 & 411.7 & 432.5 & 450.8 \\
III-1 & 377.7 & 400.4 & 425.1 & 439.6 \\
III-2 & 380.2 & 407.7 & 429.3 & 445.8 \\
\hline
\end{tabular}

Table 5. TGA results of dispersions particle

\begin{tabular}{ccccc}
\hline Sample & $\begin{array}{c}\text { Density } \\
\left(\mathrm{g} / \mathrm{cm}^{3}\right)\end{array}$ & $\begin{array}{c}\text { Open cell } \\
\text { content } \\
(\%)\end{array}$ & $\begin{array}{c}\text { Oxygen } \\
\text { index } \\
(\%)\end{array}$ & $\begin{array}{c}\text { Temperature of } \\
5 \% \text { weight loss } \\
\left({ }^{\circ} \mathrm{C}\right)\end{array}$ \\
\hline PUI foam I & 0.039 & 93.1 & 34 & 189.6 \\
PUI foam II & 0.042 & 91.8 & 34 & 186.1 \\
PUI foam III & 0.044 & 91.3 & 34 & 185.6 \\
\hline
\end{tabular}

Table 6. Properties of poly (urethane-imide) foam prepared by polymer polyols 


\section{Conclusions}

In recent years, radiation polymerization obtained significant progress, while the radiation crosslinking polymerization also obtained the great development as an important aspect of radiation polymerization. Among them, the radiation crosslinking polymerization of polyurethanes has also made remarkable progress, and have expanded to the radiation crosslinking polymerization of poly(urethane-imide)s. Poly(urethane-imide) is a newly developed polymeric materials, also, the bulk polymerization of poly(urethane-imide) become the future direction due to the advantages of low pollution to the environment. Therefore, it has very far-reaching significance that the preparation of radiation crosslinking poly(urethane-imide) via bulk polymerization. And, it is based on this consideration that the research work should be carried out in this respect.

In the work described obove, it has elaborated emphatically that the preparation of radiation crosslinking poly(urethane-imide) can be conveniently carried out by using $\gamma$-irradiation and bulk polymerization. It is worth emphasizing that the bulk preparation of radiation crosslinking poly(urethane-imide) not only is a research direction, which developed recently in radiation polymerization field, also has the vast development prospects. Moreover, radiation crosslinking OVS-poly(urethane-imide) is a kind of novel nano-composites, therefore, the research in this area will achieve further development by mutual penetration of radiation polymerization with nanometer science.

\section{Author details}

Chengfei Zhou

Beijing Research Center for Radiation Application, Key Laboratory of Radiation Technology and Advanced Materials of Beijing Academy of Science and Technology, Beijing, P.R. China

\section{References}

[1] Myong-Goo Lee. Synthesis of conductive microspheres by radiation polymerization. Polymer, 2002, 43: 4307-4309

[2] Esmaiel Jabban, Samyra Nozari. Swelling of acrylic acid hydrogels prepared by $\gamma$ radiation crosslinking of polyacrylic acid in aqueous solution. European Polymer Journal, 2000, 36(12): 2685-2692

[3] Agnes Safrany, Barbara Beiler, Krisztina Laszio, et al., Control of pore formation in macroporous polymers synthesized by single-step $\gamma$-radiation-initiated polymerization and cross-linking. Polymer, 2005, 46(9): 2862-2871

[4] Baljit Singh, S Kumar. Synthesis and characterization of psyllium-NVP based drug delivery system through radiation crosslinking polymerization. Nuclear Instruents and Methods in Physics Research Section B: Beam Interactions with Materials and Atoms, 2008, 266(15): 3417-3430 
[5] Abd H L, Mohdy E I, Agnes Safrony. Preparation of fast response superabsorbent hydrogels by radiation polymerization and crosslinking of $\mathrm{N}$-isopropylacrylamide in solution. Radiation Physics and Chemistry, 2008, 77(3): 273-279

[6] Noriaki Seko, Masao Tamada, Fumio Yoshii. Current status of adsorbent for metal ions with radiation grafting and crosslinking techniques. Physics Research Section B:Beam Interaction with Materials and Atoms, 2005, 236(1-4): 21-29

[7] Naotsugu Nagasawa, Ayaka Kaneda, Shinichi Kanazawa, et al. Application of poly(lactic acid) modified by radiation crosslinking. Nuclear Instruments and Methods in Physics Research Section B: Beam Interaction with materials and Atoms, 2005, 236(14): 611-616

[8] Radoslaw A Wach, Hiroshi Mitomo, Naotsugu Nagasawa, et al. Radiation crosslinking of carboxymethylcellulose of varius degree of substitution at high concentration in aqueous solutions of natural pH. Radiation Physics and Chemistry, 2003, 68(5): 771-779

[9] Nursel Pekel, Fumio Yoshii, Tamikazu Kume, et al. Radiation crosslinking of biodegradable hydroxypropylmethylcellulose. Carbohydrate Polymers, 2004, 55(2): 139-147

[10] Hennink W E, Nostrum C F. Novel crosslinking methods to design hydrogels. Advanced Drug Delivery Reviews, 2002, 54(1): 13-36

[11] Salmi A, Benfarhi S, Donnet J B, Decker C. Synthesis of carbon-polyaorylate nanocomposite materials by crosslinking polymerization. European Polymer Journal, 2006, 42(9): 1966-1974

[12] Baljit Singh, Manu Vashishtha. Development of novel hydrogels by modification of sterculia gum through radiation cross-linking polymerization for use in drug delivery. Nuclear Instruments and Methods in Physics Research Section B: Beam Interactions with Materials and Atoms, 2008, 266(9): 2009-2020

[13] Acharya A, Mohan H, Sabharwai S. Radiation induced polymerization and crosslinking behavior of N-hydroxy methyl acrylamide inaqueous solutions. Radiation Physics and Chemistry, 2002, 65(3): 225-232

[14] Jinhua Chen, Masaharu Asano, Tetsuya Yamaki, et al. Chemical and radiation crosslinked polymer electrolyte membranes prepared from radiation-grafted ETFE films for DMFC applications. Journal of Power Sources, 2006, 158(1): 69-77

[15] Andrzei G Chmielcwski, Mohammad Haji-Saeid, Shamshad Ahmed. Progress in radiation processing of polymers. Interaction with Materials and Atoms,2005, 236(1-4): 44-54

[16] Erdener Karadag, Dursun Saragdin, Olgun Guven. Water absorbency studies of $\gamma$ radiation crosslinked poly(acrylamide-co-2,3-dihydroxybutanedioic acid) hydrogels. Nuclear Instruments and Methods in Physics Research Section B: Beam Interaction with Materials and Atoms, 2004, 225(4): 489-496

[17] Baljit Singh, Lok Pal. Radiation crosslinking polymerization of sterculia polysaccharidePVA-PVP for making hydrogel wound dressing. Internationl Journal of Biological Macromolecules, 2011, 48(3): 501-510 
[18] Shintani H, Nakamura A. Mechanism of degradation and crosslinking of polyurethane when irradiated by gamma-rays. Journal of Applied Polymer, 1991, 42(7): 1997-1987

[19] Gorna K, Gogolewski S. The effect of gamma radidtion on molecular stability and mechanical properties of biodegradable polyurethanes for medical applications. Polymer regradation and stability, 2003, 79(3): 415-474

[20] Roger A. Assink. Radidtion crosslinking of polyurethanes. Journal of Applied Polymer Science, 1985, 30(6): 30(6): 2701-2705

[21] Shintani H, Kikuchi H, Nakamuro A. Effects of gamma-ray irradidtion on the change of characteristics of polyurethane. Journal of Applied Polymer Science, 1990, 41(3-4): 661675

[22] Beyer G, Steckenbiegler B. Radiation crosslinked thermoplastic polyurethane. Gummi Fasern Kunststoffe(Germany), 1991, 44(11): 614-617

[23] Hearon K, Gall K, Ware, T, et al. Post-polymerization crosslinked polyurethane shape memory polymers. Journal of Applied Polymer Science, 2011, 121(1): 144-153

[24] Haugen H J, Brunner M, Pellkofer F, et al, Effect of different $\gamma$-irradiation doses on cytotoxicity and material properties of porous polyether-urethane polymer. Journal of Biomedical Materials Research Part B: Applied Biomaterials, 2007, 80B(2): 415-423

[25] Jayabalan M, Lizymol P P. Effect of $\gamma$-radiation sterilization on the stability of polyurethane potting compounds based on castor oil/SMDI and caprolactone polyol/SMDI, used for hollow fibre haemodialyzer. Bulletin of materials sciences, 1997, 20(5): 727-735

[26] Keith H, Ken G, Tayler W, et al. Post-polymerization crosslinked polyurethane shapememory polymers. Journal of Applied Polymer Science, 2011, 121(1): 144-153

[27] Shintani H, Akitada N. Degradation and cross-linking of polyurethane irradiated by gamma-rays. Polymer Regradation and Stability, 1991, 32(2): 191-208

[28] Milekhin Yu M, Sadavnichii D N, Mukhacher S V, et al. Effects of $\gamma$-irradiation on the properties of (polyester urethane) elastomer. High Energy Chemistry, 2008, 42(1): 18-22

[29] Azevedo E C, Chierice G O, Neto S C. Gamma radiation effects on mechanical properties and morphology of a polyurethane derivate from caster oil. Radiation Effects and Defects in Solide, 2011, 166(3): 208-214

[30] Nouh S A, Abutalib M M. A comparative study of the effect of gamma and electron beam irradiation on the optical and structural properties of polyurethane. Radiation Effects and Defects in Solids, 2011, 166(3): 165-177

[31] Yang Y S, Lee J L. Polymerization of polyurethane-polyester interpenetrating polymer network (IPN). Macromolecules, 1987, 20 (7): 1490-1495

[32] Saad Abouzahr, Garth L Wilkes. Structure property studies of polyester- and polyetherbased MDI-BD segmented polyurethanes: Effect of one- vs. two-stage polymerization conditions. Journal of Applied Polymer Science, 1984, 29(9): 2695-2711

[33] Tetsuya Kogiso, Shin-Ichi Inoue. Synthesis and properties of elastic polyurethaneimide. Journal of Applied Polymer Science, 2010, 115(1): 242-248 
[34] Kiyotsugu Asai, Shin-Ichi Inoue, Hiroshi Okamoto. Preparation and properties of imide-containing elastic polymers from elastic polyureas and pyromellitic dianhydride. Journal of Polymer Science Part A: Polymer Chemistry, 2000, 38(4): 715-723

[35] Chuang F S. Analysis of thermal degradation of diacetylene-containing polyurethane copolymers. Polymer Degradation and Stability , 2007, 92 (7): 1393-1407.

[36] Buckley L J, Hammond P T, Rubner M F. Morphological investigation of polyurethane/diacetylene segmented copolymers. Macromolecules, 1993, 26(9): 23802382.

[37] Hu Xiao, Stanford J I, Day R J, et al. Synthesis, characterization, and structure of glassy diacetylene-containing segmented block copolyurethanes. Macromolecules, 1992, 25(2): 672-683.

[38] Nallicheri R A, Rubner M F. Thermal and mechanical properties of polyurethanediacetylene segmented copolymers. 2. Effects of diacetylene cross-polymerization. Macromolecules, 1990, 23(4): 1017-1025.

[39] Nallicheri R A, Rubner M F. Thermal and mechanical properties of polyurethanediacetylene segmented copolymers. 1. Molecular weight and annealing effects. Macromolecules, 1990, 23 (4):1005-1016.

[40] Nitzsche S A, Hsu S L, Hammond P T, et al. Spectroscopic study of domain ordering in diacetylene-containing model polyurethanes. Macromolecules, 1992, 25(9): 2391-2396.

[41] Nallicheri R A, Rubner M F. Influence of cross-linking on the hysteresis behavior of poly(urethane-diacetylene) segmented copolymers. Macromolecules, 1991, 24(2): 526529

[42] $\mathrm{Hu}$ X, Breach C D, Young R J. Elucidation of the hard segment transition in a diacetylene-containing copolyurethane using modulated differential scanning calorimetry. Polymer, 1997,38(4): 981-983

[43] Hammond P T, Nallicheri R A, Rubner M F. Examination of the strain-induced orientation of hard segment domains in 4,4-methylenebis(phenyl isocyanate)-based polyurethane-diacetylene segmented copolymers. Materials Science and Engineering A, 1990, A126(1-2): 281-287

[44] Nallicheri R A, Rubner M F. Investigations of the mechanochromic behavior of poly(urethane-diacetylene) segmented copolymers. Macromolecules, 1991, 24(2): 517525

[45] Huang S J, Edelman P G. Polyetherurethaneureas containing diacetylene in the hard segments. Journal of Applied Polymer Science, 1990, 41(1-2): 3-11

[46] Estrada M R, Burillo G, Ogawa T. Diacetylene-containing polymers, II. Polyesters and polyurethanes containing $\mathrm{m}, \mathrm{m}$ prime -butadiynylenedibenzyl groups. Polymers for Advanced Technologies, 1992,3(8):419

[47] Chengfei Zhou, Wei Cao, Tong Zhai, et al. Bulk preparation and $\gamma$-ray irradiationinduced effect of poly(urethane-imide) using 2-hydrooxyethyl methylacrylate as end capping reagent. Polymer Materials Science and Engineering, 2011, 27(6): 15-17,21 
[48] Patel H S, Patel B P, Patel D B. Synthesis, Characterization and glass reinforcement of poly(ester amido imide)s. International Journal of Polymeric Materials, 2009, 58(12): 625-635

[49] Patel H S, Mathur A B, Bhardwaj I S. Synthesis and characterization of modified polyimides: poly(urethane-imide). Journal of Macromolecular Science, Part A: Pure and Applied Chemistry, 1995, 32(12): 2925-2034

[50] Patel J C, Patel K D, Daraji J M. Synthesis, characterization, and glass fiber reinforced composites of poly(urethane-imide)s.International Journal of Polymeric Materials, 2003, 52(5): 345-359

[51] Jiangxuan Song, Guangxin Chen, Yun Ding, et al. Preparation and characterization of epoxy resin modified with alkoxysilane- functionalized poly(urethane-imide) by the sol-gel process. Polymer International, 2011, 60(11): 1594-1599

[52] Hamid Yeganeh, Mohammad Atai, Pejman Hojati Talemi. Synthesis, characterization and properties of novel poly(urethane-imide) networks as electrical insulators with improved thermal stability. Macromolecular Materials and Engineering, 2006, 291(7): 883-894

[53] Hamid Yeganeh, Shahram Mehdipour-Ataei, Mehdi Ghaffari. Preparation and properties of novel poly(urethane-imide)s via blending of reactive polyimide and epoxy-terminated urethane prepolymers. High Performance Polymers. 2008, 20( 2): 126145

[54] Tetsuya Kogiso, Shin-Ichi Inoue. Synthesis and properties of elastic polyurethaneimide. Journal of Applied Polymer Science, 2010, 115(1): 242-248

[55] Jong-Young Jeon, Tae-Moon Tak. Synthesis and characterization of block copoly(urethane-imide). Journal of Applied Polymer Science, 1996, 62(5): 763-769

[56] Chia Zheng Cheng, Yeo Swee Chengl. Preparation of nanoporous polyimide films from poly(urethane-imide) by thermal treatment. .Macromolecular Materials and Engineering, 2003, 288(9): 730-736

[57] Jin Liu, Zhen Li, Xiaolie Luo, Dezhu Ma. Synthesis, structure, and properties of polyimide and polyurethane-urea-imide copolymers. Journal of Polymer Science Part B: Polymer Physics, 2004, 42(2): 216-225

[58] Gnanarajan T Philip, Nasser A Sultan, Iyer N. Padmanabha,et al.Synthesis of poly(urethane-imide) using aromatic secondary amine-blocked polyurethane prepolymer. Journal of Polymer Science Part A: Polymer Chemistry, 2000, 38(22): 40324037

[59] Mi-Hee Park, Wonbong Jang, Seung-Jin Yang,et al. crosslinked networks. Journal of Applied Polymer Science, 2006, 100(1): 113-123

[60] Gnanarajan T Philip, Iyer N. Padmanabha. Poly(urethane-imide)s from blocked polyurethane prepolymer and pyromellitic dianhydride: effect of alkali metal alkoxides and phenoxides and substituents on the blocking agent in the polymerization reaction. Journal of Macromolecular Science, Part A: Pure and Applied Chemistry, 2001, 38(8): 807-820 
[61] Vladimír Šindelář, Petr Sysel, Vladimír Hynek, et al. Transport of gases and organic vapours through membranes made of poly(amide-imide)s crosslinked with poly(ethylene adipate). Collect. Czech. Chem. Commun. 2001, 66, 533-540

[62] Hossein Behniafar. Direct synthesis of new soluble and thermally stable poly(urethaneimide)s from an imide ring-containing dicarboxylic acid using diphenylphosphoryl azide. Journal of Applied Polymer Science, 2006, 101(2): 869-877

[63] Min Zuo, Tsutomu Takeichi. Novel method for the preparation of poly(urethaneimide)s and their properties. Journal of Polymer Science Part A: Polymer Chemistry, 1997, 35(17): 3745-3753

[64] XiuMin Qin, XiaoHui Yang, XinLing Wang. Synthesis and characterization of poly(imide-urethane) based on novel chain-extender containing both imide and sulphone functions. Journal of Polymer Science Part A: Polymer Chemistry, 2005, 43(19): 4469-4477

[65] Choonkeun Lee, Iyer N. Padmanabha, Kyungwook Min, et al. Synthesis and characterization of novel poly(amide-imide)s containing 1,3-diamino mesitylene moieties. Journal of Polymer Science Part A: Polymer Chemistry, 2004, 42(1): 137-143

[66] Pinggui Liu, Qingfang Zhang, Lihua He,et al. Thermal and mechanical properties of poly(urethane-imide)/epoxy/silica hybrids. Journal of Applied Polymer Science, 2010, 117(6): 3722-3728

[67] Chengfei Zhou, Wei Cao, Tong Zhai, et al. Preparation and characterization of radiation crosslinking polyurethane and its POSS-containing composites. Polyurethane Industry, 2011, 26(3): 9-12

[68] Efrat T,Dodiuk H,Kenig S,et al. Nanotailoring of polyurethane adhesive by polyhedral oligomeric silsesquioxane (POSS). Journzl of Adhesion Science and Technology, 2006, 20(12):1413-1430

[69] Madbouly S A, Otaigbe J U, Nanda A K, et al. Rheological behavior of POSS/polyurethane-urea nanocomposite films prepared by homogeneous solution polymerization in aqueous dispersions. Macromolecules, 2007,40 (14) 4982-4991

[70] Bliznyuk V N, Tereshchenko T A, Gumenna M A, et al. Structure of segmented poly(ether urethane)s containing amino and hydroxyl functionzlized polyhedral oligomeric silsesquioxanes (POSS). Polymer,2008,49(9):2298-2305

[71] Dnanasekaran D, Reddy B S R. Advanced materials, CNTs, Particles, Films and Composites, Chapter 4: Synthesis and characterization of poly(urethane-imide)-POSS nanocomposites. Nanotechnology,2011,1:445-448

[72] Jiangxuan Song, Guangxin Chen, Gang $\mathrm{Wu}$, et al. Thermal and dynamic mechanical properties of epoxy resin/poly(urethane-imide)/polyhedral oligomeric silsesquioxane nanocomposites. Polymers for Advanced Technologies, 2011, 22(12):2069-2074

[73] Chengfei Zhou, Jianmei Guo, Tong Zhai. Research of radiation grafting polyurethane foam. China Rubber/Plastics Technology and Equipment, 2005, 31(11): 32-35 
[74] Fenin A A, Ermakov V I, Revina A A. Radidtion-chemical synthesis of polymer polyols and related composites, Theoretical Foundations of chemical Engineering, 2008, 42 (5):662-665

[75] Chengfei Zhou. Advance in polymer polyols with high solid content. China Synthetic Rubber Industry, 2005, 28(5): 321-324 